\title{
ANÁLISE DE PERFIL DE GRAVAÇÃO EM MÁRMORES COM UTILIZAÇÃO DE TECNOLOGIA LASER 3D
}

Clarissa Sartori Ziebell

Universidade Federal do Rio Grande do Sul clarissa.ziebell@ufrgs.br

Jorge Ramos

Universidade Federal do Rio Grande do Sul jramos@brazildesign.com.br

\author{
Fábio Pinto da Silva \\ Universidade Federal do Rio Grande do Sul \\ fabio.silva@ufrgs.br \\ José Luis Farinatti Aymone \\ Universidade Federal do Rio Grande do Sul \\ aymone@ufrgs.br \\ Underléa Miotto Bruscato \\ Universidade Federal do Rio Grande do Sul \\ underlea.bruscato@ufrgs.br
}

Resumo: O objetivo deste artigo foi pesquisar o comportamento e as características de gravação a laser do mármore branco a fim de que fosse possível parametrizar soluções e recursos técnicos para o desenvolvimento de produtos com acabamento final personalizável. Para tanto, comparouse o mármore branco nacional e o mármore com coloração semelhante, importado de Carrara, uma região da Toscana, Itália. Como resultado, foi constatado que no mármore branco nacional as profundidades das gravações são imprevisíveis e não homogêneas. No mármore de Carrara, por sua vez, percebe-se que quanto maior o percentual de preto da imagem gravada, maior é a profundidade de gravação obtida. Contudo, não é possível prever com precisão a dimensão da profundidade, já que ela se mostrou sempre com alguma variação.

Palavras-chave: gravação a laser, digitalização 3D, mármore.

Abstract: The aim of this article is searching the behavior and laser engraving characteristics of white marble in order to make it possible parameterize solutions and technical resources for the development of products with finishing customizable. Therefore, it was compared the national white marble and marble with similar coloring, imported from Carrara, a region of Tuscany, Italy. As a result, it is found that in the national white marble the depths of the recordings are unpredictable and not homogenous. In Carrara marble, in turn, we can see that the higher the black percentage of the recorded image, the greater the depth obtained recording. However, it is not possible to predict with precision the size of the depth, since it has always shown with some variation.

Keywords: laser engraving, 3D Scanning, marble 


\section{INTRODUÇÃO}

O Brasil é destaque mundial na produção e exportação de rochas ornamentais, pertencendo ao grupo de maiores produtores e exportadores mundiais, com uma produção em 2014 de mais de 10 milhões de toneladas de rochas ornamentais, abrangendo mármores, granitos, ardósia, calcários e outros (CHIODI FILHO, 2015). A comercialização no mercado interno e externo ultrapassa as 1.200 variedades de rochas ornamentais, com mais de 1.500 pedreiras ativas no país. O consumo interno ultrapassa os 75 milhões de $\mathrm{m}^{2}$ de chapas, 130 milhões de toneladas, das quais aproximadamente $20 \%$ são de chapas beneficiadas, de mármore e travertinos. Na contrapartida, as importações brasileiras de rochas ornamentais ultrapassam os 45 milhões de toneladas (STUMPF, 2009). Nesse universo, o mármore branco ocupa papel de relevância, pois é um dos quatro padrões mais comercializados no mercado interno. A exportação de rochas ornamentais brasileiras é praticamente de produtos sem valor agregado, composta por ladrilhares e chapas planas sem regularização de perfil (STUMPF, op.cit.).

Nesse artigo foi pesquisado o comportamento e características de gravação 3D do mármore branco a fim de que se possam parametrizar soluções e recursos técnicos para o desenvolvimento de produtos com acabamento final personalizável e maior valor agregado. Sabe-se que diferentes profundidades podem ser obtidas em uma gravação a laser através do uso de imagens com diferentes tons de preto (CIDADE, 2009 e SOARES et al., 2015). Contudo, não é conhecida a relação entre tom de preto e profundidade da gravação atingida. Este trabalho busca analisar se há uma relação entre o tom de preto de uma imagem e a profundidade de gravação desta imagem em mármore de coloração branca.

Como forma de análise, foram preparadas imagens com diferentes tons do cinza ao preto, com variação intermitente e com variação contínua, indo de $10 \%$ do preto a $100 \%$. Essas imagens foram gravadas em peças de mármore branco (nacional) e Carrara (importado), utilizando tecnologia laser em diferentes velocidades de gravação. A partir de testes iniciais, foi parametrizada a velocidade mais baixa e a mais alta, nas quais pudessem ser obtidos resultados visíveis nas peças de mármore. Após a gravação, a profundidade foi avaliada através da digitalização tridimensional das peças e posterior análise das seções.

\section{DESENVOLVIMENTO}

A seguir, são apresentados os objetivos e a metodologia de pesquisa adotada neste artigo.

\subsection{Objetivos}

O objetivo deste trabalho é verificar a relação entre a porcentagem de cor preta na imagem preparada com resolução de 200 dpi, e a profundidade da gravação 3D correspondente. Espera-se ainda encontrar quais dos parâmetros analisados produzem melhor resultado e são mais adequados para a gravação nos dois tipos de mármore estudados (Nacional e de Carrara).

\subsection{Metodologia}

No desenvolvimento do trabalho foram adotadas as seguintes etapas:

1a) Seleção e preparação das peças de mármores;

2a) Preparação das imagens para os testes de gravação a laser; 
3a) Gravações a laser, com o equipamento Mira 3007;

4a) Limpeza e preparação da superfície das peças;

5a) Digitalização 3D com o equipamento Tecnodrill Digimil 3D;

6a) Transformação dos dados da digitalização em malhas 3D;

7ạ) Análise de seç̧ões no software Geomagic Qualify.

Após o término destas etapas foi possível analisar os resultados obtidos de acordo com os parâmetros utilizados nas gravações, nos diferentes tipos de mármore, nacional e importado.

\subsubsection{Seleção dos Mármores}

A seleção dos tipos de rochas ornamentais para os testes foi feita após uma visita a algumas marmorarias e distribuidores de pisos e ladrilhos de rochas, identificação de maior demanda e verificação da disponibilidade na região. Conforme Souza et al. (2007), a produção brasileira de rochas ornamentais distribui-se por 19 estados da federação, sendo que o Espírito Santo assume a liderança, com $46 \%$ do total produzido, responsável por $75 \%$ da extração de mármores. No Brasil temos vários nomes comerciais para o mármore branco, tais como Caledônia White, Branco Clássico, Mármore Branco, Calendária White, esses no Espírito Santo, além do Branco Paraná no Paraná, Italva e Cintilante no Rio de Janeiro. De acordo com visitas a marmorarias da região da grande Porto Alegre, os mármores mais procurados para revestimento de pisos e paredes são os mármores brancos, nacionais e importados. Dentre as peças obtidas nessas marmorarias, de diversas cores, foram selecionadas as peças brancas, porque, além de serem encontradas mais facilmente na região, foram as que apresentaram melhor resultado geral com a gravação, oferecendo um jogo de luzes interessantes na formação dos contrastes. Assim, ensaios foram realizados com o mármore branco nacional (figura $1 \mathrm{~A}$ ), produzido no Espírito Santo e o branco de Carrara (figura 1B), importado da região da Toscana, Itália.

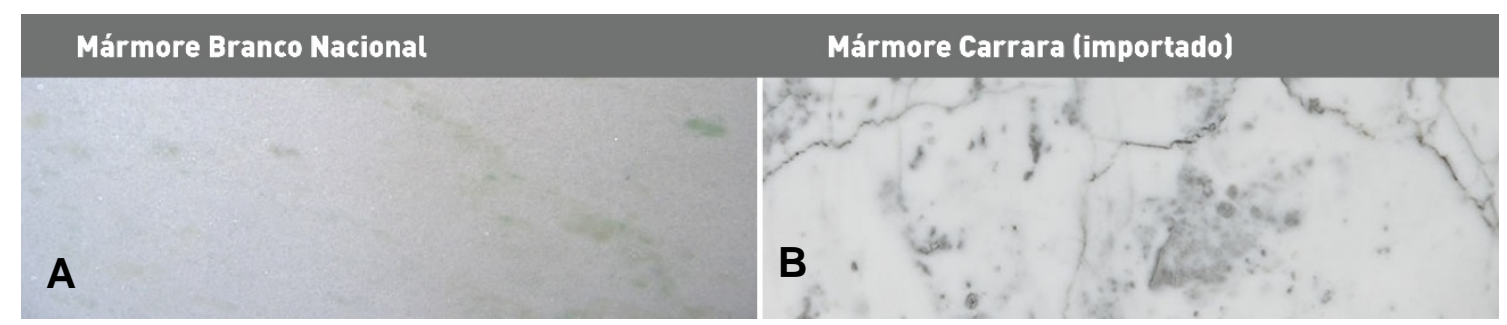

Figura 1 - Mármore Branco Nacional / Mármore Carrara (importado)

Fonte: Fotos dos autores.

\subsubsection{Preparação das imagens para os testes de gravação a laser}

As imagens utilizadas para gravação foram preparadas pelos autores. Caracterizam-se por serem de duas tipologias de gradientes de preto, entre $10 \%$ e $100 \%$. Parte da imagem foi feita com gradiente contínuo, ou seja, com variação de tonalidade entre o preto $100 \%$ e retícula a $10 \%$, sem intervalos definidos, e parte em gradiente intermitente, com retângulos separados dentre si. Essas imagens foram exportadas em padrão GIF, preto e branco, com resolução de 200 dpi, seguindo as orientações do fabricante do equipamento laser, Mira 3007. 


\subsubsection{Gravação a laser}

As gravações foram feitas no equipamento Mira 3007, da empresa Automatisa Sistemas. Foram utilizadas peças no formato $4 \times 2 \mathrm{~cm}$. As gravações foram feitas usando as imagens preparadas pelos autores. O total de peças gravadas foi de 16 unidades, sendo 8 do mármore nacional e 8 do mármore de Carrara. Para cada um dos conjuntos de 8 peças foram testadas as velocidades de gravação de $1,0 \mathrm{~m} / \mathrm{min}, 0,75$ $\mathrm{m} / \mathrm{min}, 0,5 \mathrm{~m} / \mathrm{min}$ e $0,25 \mathrm{~m} / \mathrm{min}$. Estas velocidades foram definidas em função de trabalhos semelhantes (SOARES et al, 2015). As velocidades de gravação foram repetidas a fim de que se pudesse ter um parâmetro de espectro maior para análises. Cada conjunto de mármore foi testado duas vezes, com a potência máxima do equipamento, $60 \mathrm{~W}$ (figura $2 \mathrm{~A}$ e $2 \mathrm{~B}$ ).

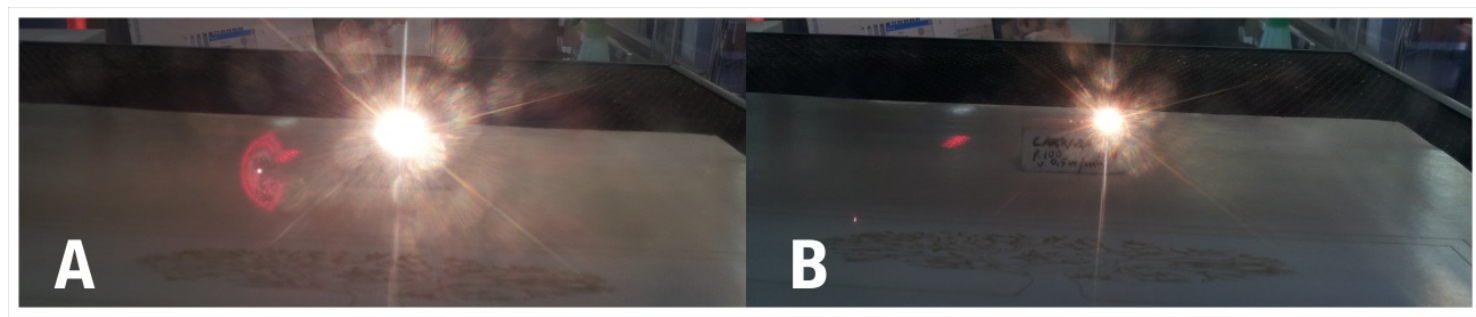

Figura 2 - Gravações em diferentes velocidades. Fotos dos autores.

Fonte: Elaborada pelos autores.

\subsubsection{Limpeza e preparo das superfícies das peças}

Após as gravações cada peça foi cuidadosamente limpa com escovas de cerdas médias e macias. Por tratar-se de peças com superfície polida, foi utilizado um pó (Revelador Metal-chek D-70) para tornar a superfície mais fosca, pulverizando assim uma nuvem tênue que cobriu parcialmente o brilho da peça, proporcionando uma digitalização 3D mais eficiente.

\subsubsection{Digitalização 3D das gravações}

Os resultados obtidos nas gravações de testes, depois de preparadas, foram digitalizados com tecnologia laser no equipamento Tecnodrill Digimil 3D (figura 3). A resolução (espaçamento entre pontos medidos nos eixos $X$ e $Y$ ) foi de $0,01 \mathrm{~mm}$, com a utilização de uma lente de $75 \mathrm{~mm}$, a qual fornece uma precisão de 0,006 mm na profundidade (eixo Z).

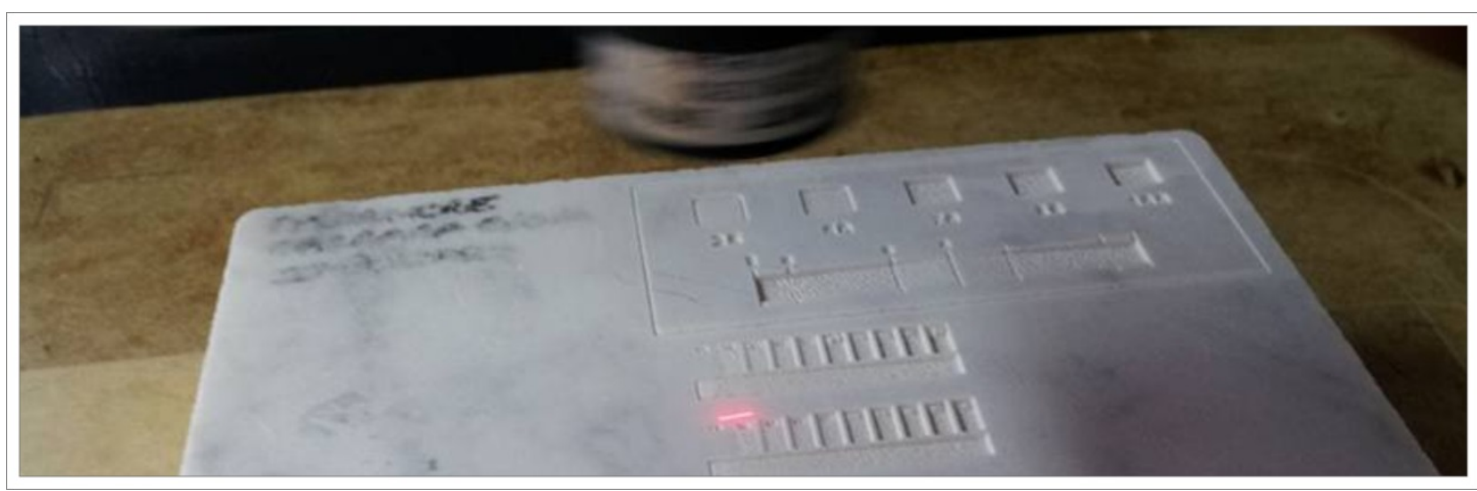

Figura 3 - Digitalização 3D da amostra gravada com velocidade: 1,0 m/min.

Fonte: Elaborado pelos autores, com base na pesquisa realizada. 


\subsubsection{Transformação dos dados da leitura laser em uma malha 3D}

Cada digitalização gerou uma nuvem de pontos, que foi posteriormente transformada em uma malha triangular. As figuras $4 A$ e $4 B$ mostram o resultado da nuvem de pontos e a posterior transformação em malha. $A$ figura $4 B$, já transformada em malha, mostra também a posição da seção que foi posteriormente analisada. Este processo foi realizado com o uso do software Geomagic Qualify.

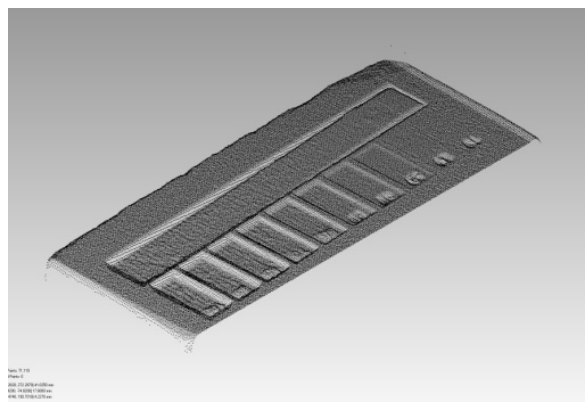

Figura 4A - Nuvem de pontos de uma das amostras digitalizadas.

Fonte: Elaborado pelos autores, com base na pesquisa realizada.

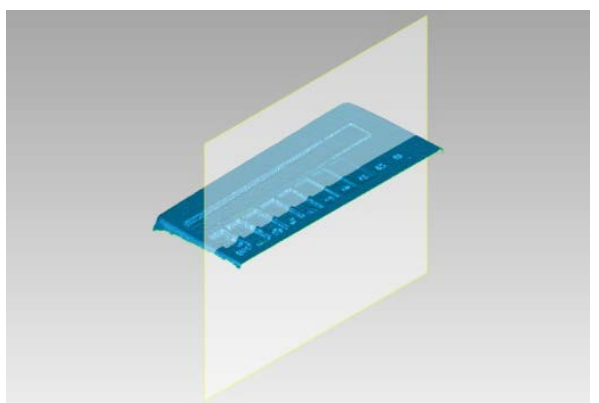

Figura 4B - Transformação da nuvem de pontos em uma malha tridimensional. $O$ plano vertical mostra a posição as seções avaliadas nesse artigo. Fonte: Elaborado pelos autores, com base na pesquisa realizada.

\subsubsection{Análise das seções}

Com a malha 3D, foram realizadas as análises das secções transversais das peças usando o software Geomagic Qualify, do qual obteve-se as informações das profundidades e rugosidades atingidas em cada peça. Esta análise permitiu não somente verificar a relação direta entre os tons de preto e a profundidade de gravação resultante, mas também que fossem definidos os parâmetros que melhor se adequaram para as gravações das peças de mármore.

\section{CONCLUSÃO}

A seguir, são apresentados os resultados encontrados e sua posterior análise. As discussões realizadas abrangem a relação entre a porcentagem de preto da imagem de gravação, a velocidade de gravação e as seções.

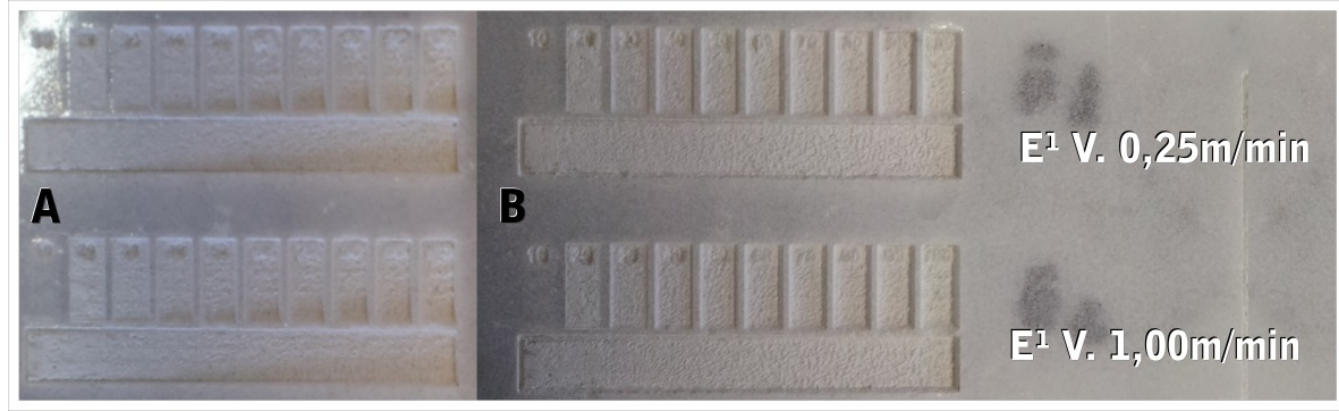

Fig.5 Amostras das peças, 5A, peça de Carrara, 5B, peça nacional. Ambas gravadas nas velocidades indicadas.

Fonte: Fotos obtidas pelos autores.

\subsection{Análise dos resultados}

A primeira análise foi das seções obtidas no software Geomagic Qualify, tanto para o mármore de Carrara (figura 6), quanto para o mármore nacional (figura 7). 
Destaca-se na figura 6 que os rebaixos são planos, com pouca irregularidade. Além disso, percebem-se muito claramente na figura 6 que diferentes tons de preto geram diferentes profundidades. Isso demonstra que o mármore de Carrara é adequado para as gravações a laser.

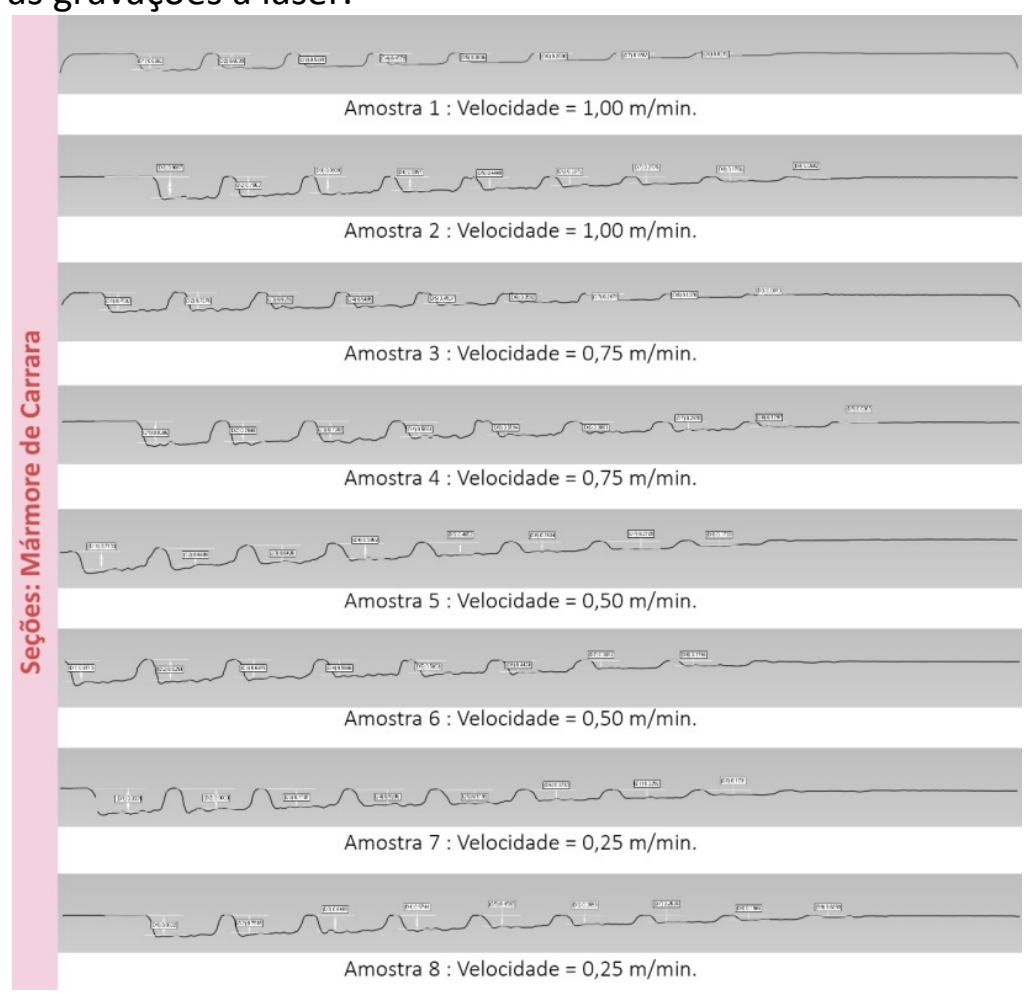

Figura 6 - Seções das Amostras 1 a 8, mármore de Carrara (os tons de cinza estão em ordem decrescente, à esquerda está o $\mathbf{1 0 0 \%}$ preto).

Fonte: Elaborado pelo autor, com base na pesquisa realizada.

Já na figura 7 observa-se que o mesmo não ocorre para o mármore nacional. Pode-se perceber que os rebaixos, que deveriam ser planos, ficaram muito irregulares. Além disso, a influência da quantidade de preto não pode ser claramente percebida. 


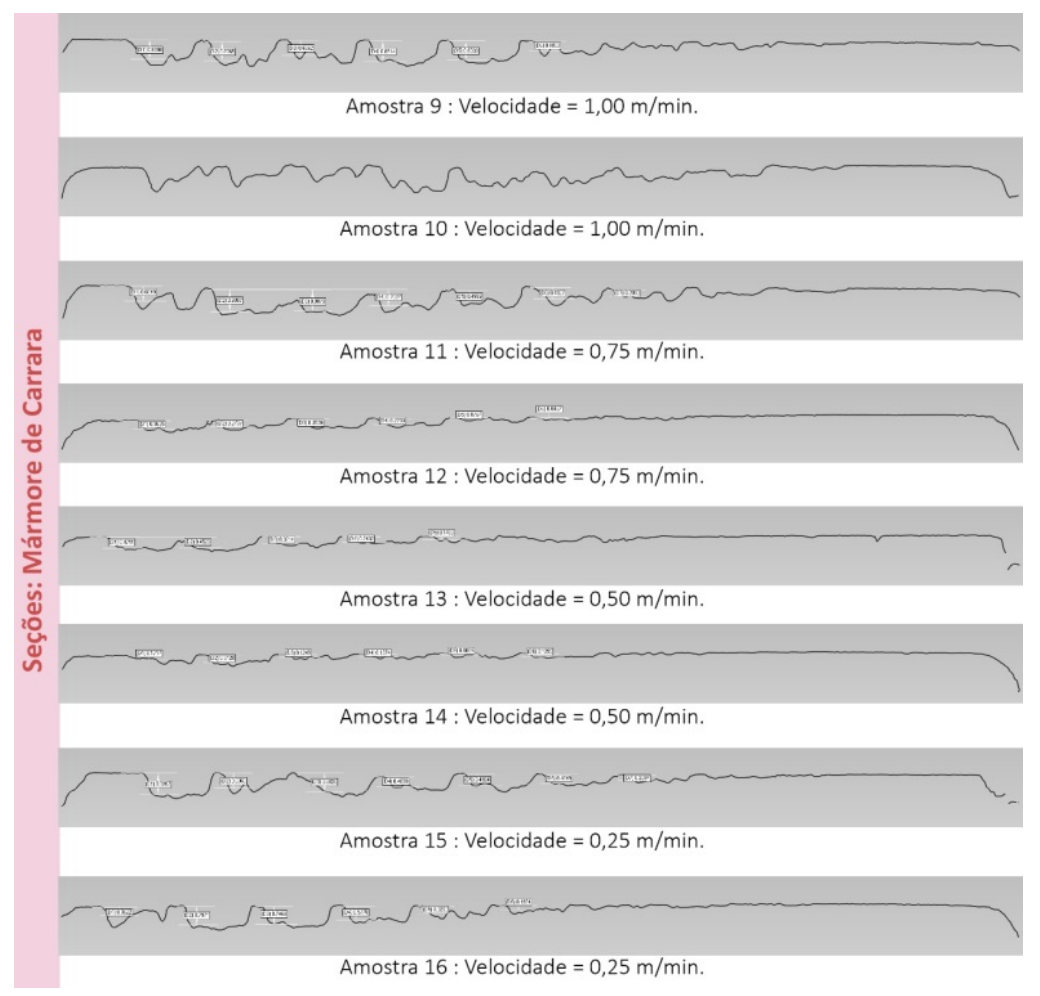

Figura 7 - Seções das Amostras 9 a 16, mármore Nacional (os tons de cinza estão em ordem decrescente, à esquerda está o $100 \%$ preto).

Fonte: Elaborado pelos autores

A fim de facilitar as análises, foi elaborado um gráfico para cada tipo de mármore que relaciona o tom de preto com a profundidade alcançada (figuras 8 e 9). $\mathrm{Na}$ figura 8 a influência da quantidade de preto também ganha destaque para $\mathrm{o}$ mármore de Carrara. Apesar de não ser possível determinar exatamente qual será a profundidade alcançada, pode-se ter uma previsão. Já a variação na velocidade, para as velocidades ensaiadas, apresentou menor influência nos resultados.

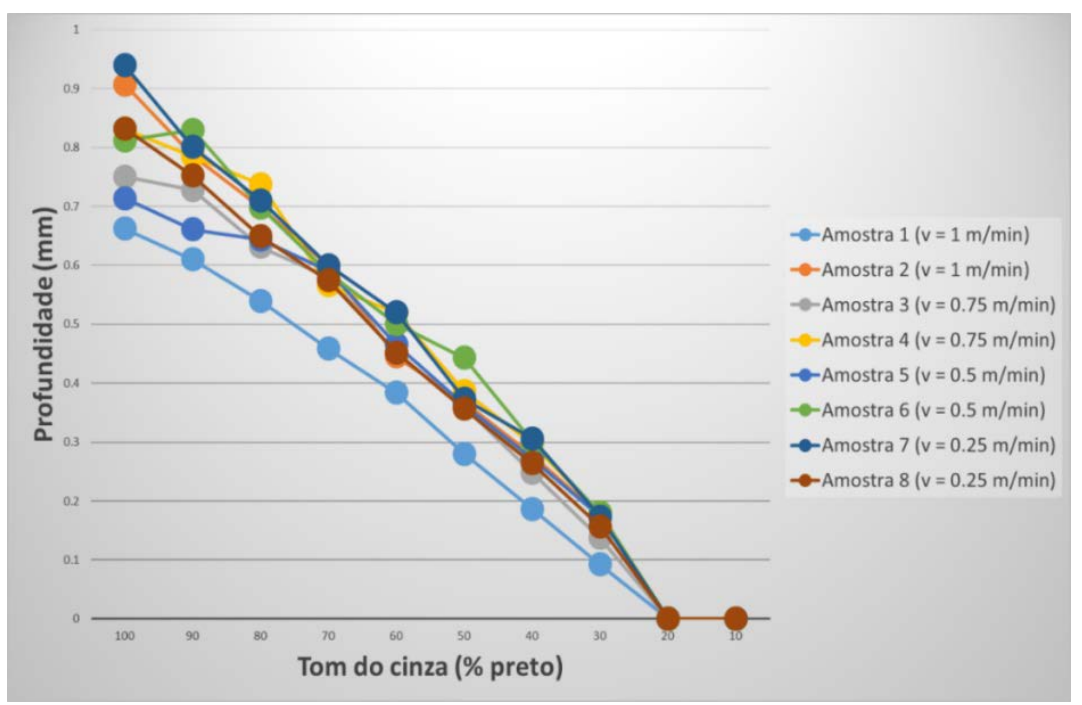

Figura 8 - Gráfico comparativo entre as 8 amostras do mármore de Carrara. Fonte: Elaborado pelo autor, com base na pesquisa realizada. 
A figura 9, por sua vez, demonstra que o mármore Nacional não permite previsão com relação a profundidade que será alcançada. Pode-se apenas perceber que a tendência é atingir maiores profundidades com maiores quantidades de preto, 0 que também pode ser notado na figura 7. Ainda, todas as seções das peças de mármore nacional possuem um perfil heterogêneo, o que ficou evidente pela dificuldade de medição das profundidades.

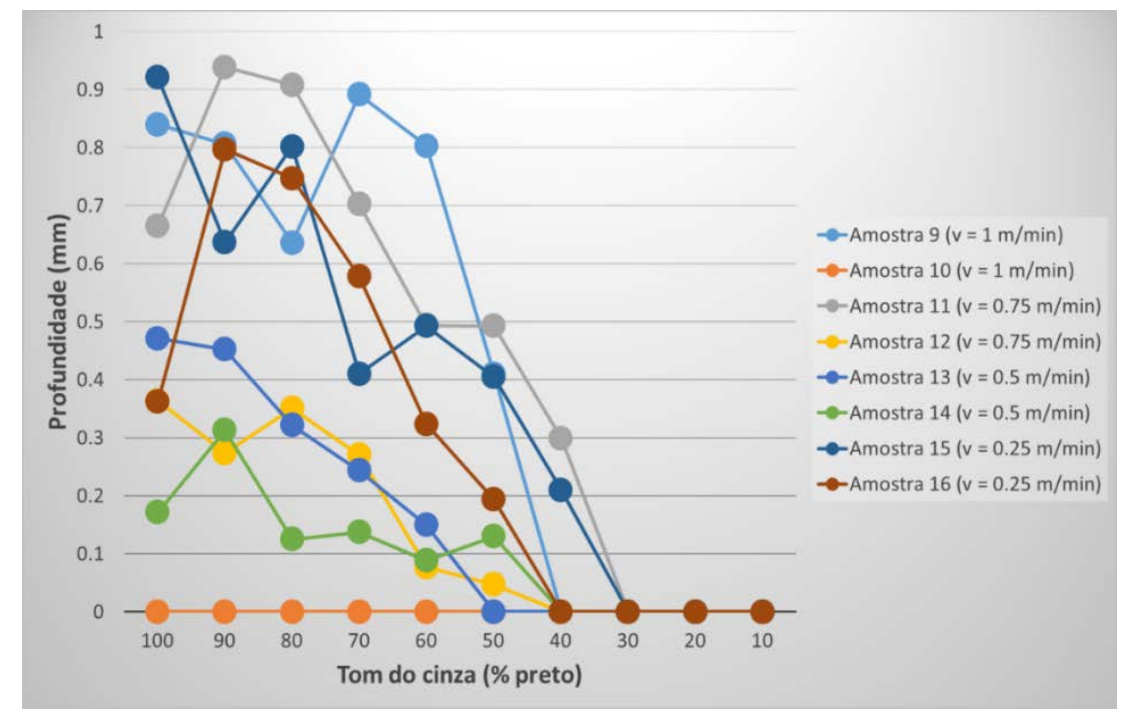

Figura 9 - Gráfico comparativo entre as 8 amostras do mármore Nacional. Fonte: Elaborado pelo autor, com base na pesquisa realizada.

\subsection{Considerações finais}

O presente estudo permite concluir que os processos de gravação 3D, através da tecnologia laser são viáveis para produções customizadas, porém, observadas as seguintes questões:

- Nas análises, o mármore de Carrara apresentou mais eficiência no processo de gravação, proporcionando uma superfície de corte bem delimitada e de fundo de corte com menores dimensões e imperfeições. Portanto, a homogeneidade do substrato, nos seus elementos que produzem a pigmentação do mármore, deve ser observada. O padrão cromático nos mármores é definido por minerais acessórios e impurezas, pois os seus constituintes principais são a calcita e a dolomita, normalmente brancos (RIBEIRO, 2011). Nesses casos, a exemplo do mármore de Carrara, sugerimos usar os parâmetros de gravação testados acima, como uma referência inicial, confirmando os resultados em testes específicos para cada peça a ser gravada.

- Para fins comerciais, sugere-se a utilização de equipamento de maior potência de gravação, a fim de que possibilite a produção com baixo tempo de processamento.

- Sugere-se sempre testar o mármore, por amostragem de lote, a fim de que se estabeleçam parâmetros de configuração adequados a cada partida do equipamento de gravação. 
- Análises mais específicas quanto à estrutura e composição mineral das peças a serem gravadas podem ser usadas como apoio à parametrização de gravação.

\section{REFERÊNCIAS}

CHIODI FILHO, Cid. Balanço das exportações brasileiras de rochas ornamentais e de revestimento no primeiro semestre de 2014. São Paulo: Associação Brasileira da Indústria de Rochas Ornamentais, 2015. Disponível na internet por http em: <http://www.ivolution.com.br/mais/fotos/6/17/3397/Informe_01_2015.pdf>. Acesso em 09 mai. 2015.

CIDADE, Mariana Kuhl. Caracterização e Padronização do Processo de Gravação a laser em Ágata Aplicado ao Design de Jóias. 2009. 172f. Dissertação (Mestrado). Universidade Federal do Rio Grande do Sul, Programa de Pós-Graduação em Design.

RIBEIRO, Wagner José Medeiros. Estudo comparativo de alterabilidade acelerada de três fácies comerciais do sienito marrom imperial. 2011, p. 13. Dissertação (Mestrado) - Universidade Federal de Pernambuco. CTG/UFPE - Programa de Pós Graduação em Engenharia Mineral, 2011.

SOUZA, V.C.; SOUZA, J.C.; ROLIM FILHO, J.L. Diagnóstico do Setor de Rochas Ornamentais e de Revestimentos do Estado de Pernambuco. III Congresso Brasileiro de Rochas Ornamentais. Natal, 2007.

STUMPF, Elisabeth Tempel; ROMANO, Cátia Maria; BARBIERI, Rosa Lía; HEIDEN, Gustavo; FISCHER, Síntia Zitzke; CORRÊA, Lauís Beisolara. Características Ornamentais de Plantas do Bioma Pampa. Campinas: Revista Brasileira de Horticultura Ornamental, 2009. Disponível na internet por http em: <http://132.248.9.34/hevila /Revistabrasileiradehorticulturaornamental/2009/vol15/no1/6.pdf $>$. Acesso em 31 jul. 2015. 